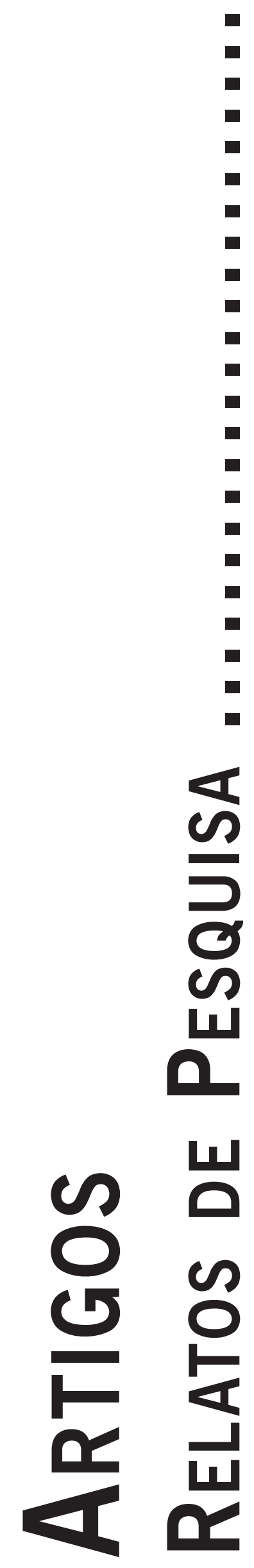




\title{
PATERNIDADE ADOTIVA: CONJUGANDO AFETOS CONSENTIDOS
}

\author{
Adoptive Paternity: Conjugating Consented Affections \\ Paternidad Adoptiva: La Combinación de Afectos Consentidos
}

ELLEn FERnanda Gomes da Silva

Suely EMilia de Barros SANTOS

\begin{abstract}
Resumo: Ao percorrer os meandros da temática do presente estudo, verificou-se o expoente número de trabalhos acerca das masculinidades e paternidades. Conquanto, esse crescimento não investe expressivamente na reflexão da paternidade adotiva. Deste modo, esta pesquisa apresenta-se como relevante, uma vez que estes são fenômenos presentes no cenário social. Nessa direção, este trabalho objetiva compreender a experiência de ser pai adotivo, via entrevista aberta, a "entrevista Clínica de Pesquisa", a partir da vivência de Davi - integrante de um Grupo de Estudo e Apoio à Adoção. A interpretação dos depoimentos foi realizada através da "Analítica do Sentido". Dentre as possibilidades compreensivas, foi ressaltado, no depoimento de Davi, o questionamento sobre a hegemonia biológica dos arranjos familiares, apresentando a afetividade como marca para os relacionamentos familiares. Nessa direção, esta pesquisa põe em foco um diálogo sobre o exercício das paternidades relacionadas à adoção, em especial, às chamadas "adoções necessárias", as quais se referem às crianças maiores e adolescentes.
\end{abstract}

Palavras-chave: Adoção; Família; Paternidade.

\begin{abstract}
When going through the intricacies of this study's subject, it was found an exponent number of works about masculinities and paternities. However this increase does not shows significantly reflection about adoptive paternity. Thus, this research is presented as relevant, since these phenomena are present in the social context. Thereby this work aims to understand the experience of being a adoptive father, via open interview, the "Clinical Research interview", through Davi's experience member of a Study and Support Group for Adoption. The interpretation of the interviews was realized through the "Analytic of Sense". Among the comprehensive possibilities, it was bounced in Davi's testimony the questioning of the biological family arrangements hegemony, presenting the affection as a trade mark for family relationships. In this sense, this research highlights a dialogue about the exercise of paternity related to the adoption, in particular the so-called "necessary adoptions", which refer to older children and adolescents.
\end{abstract}

Keywords: Adoption; Family; Paternity.

Resumen: A medida que se desplaza por las complejidades del tema de este estudio, si el exponente del número de documentos sobre la masculinidad y la paternidad. Si bien este crecimiento no invierte significativamente en el reflejo de la paternidad adoptiva. Por lo tanto, este estudio se presenta como relevante, ya que estos fenómenos están presentes en el entorno social. En este sentido, este trabajo tiene como objetivo comprender la experiencia de ser un padre de crianza, a través de entrevista abierta, la "entrevista de Investigación Clínica", de la experiencia de David - um miembro de una Comisión de Estudio y Apoyo a la Adopción. La interpretación de las entrevistas se llevaron a cabo a través de la " analítica del sentido. "Entre las posibilidades integral, se puso de relieve en el testimonio de David, el cuestionamiento de la hegemonía de los arreglos familiares biológicos, con afecto como marca para las relaciones familiares. En este sentido, esta investigación pone de relieve el diálogo sobre el ejercicio de la paternidad en relación con la adopción, en particular los llamados "adopciones necesario", que se refieren a los niños mayores y adolescentes.

Palabras clave: Adopción; Familia; Paternidad.

\section{Introdução}

Não digas: Este que me deu corpo é meu Pai.

Esta que me deu corpo é minha Mãe.

Muito mais teu Pai e tua Mãe são os que te fizeram

em Espírito.

E esses foram sem número.

Sem nome.

De todos os tempos.

Deixaram o rastro pelos caminhos de hoje.

Todos os que já viveram.
E andam fazendo-te dia a dia

Os de hoje, os de amanhã.

E os homens, e as coisas todas silenciosas.

A tua extensão prolonga-se em todos os sentidos.

O teu mundo não tem pólos.

E tu és o próprio mundo.

(Cecília Meireles)

Na contemporaneidade tem-se ampliado o debate a respeito da parentalidade adotiva. Em virtude das reconfigurações familiares, bem como das metamorfoses 
sociais, culturais e jurídicas, as famílias adotivas vêm saindo da clandestinidade e ganhando o seu espaço enquanto modo de ser família; e, semelhantemente, o lugar do pai no contexto familiar tem sido debatido uma vez que, também apresentava-se forasteiro, apenas atrelado ao exercício de provedor do lar.

Feitas as considerações acima mencionadas, importa salientar a relevância acadêmica deste estudo, tomando como partida a visitação em sites como Google Acadêmico, Portal de teses e dissertações da Coordenação de Aperfeiçoamento de Pessoal de Nível Superior (CAPES), levantamento deste último realizado entre os anos de 1987 a 2009, e a Base de Artigos Científico do Scientif Eletronic Library Online (SciELO), na qual foi identificada uma escassez de produções científicas que articulem o tema da paternidade com a adoção. Além disso, vale ressaltar que muitas das produções acadêmicas encontradas nos órgãos citados acima, concentram-se na criança adotiva. Com relação à paternidade, esse tema foi pouco explorado pela Psicologia, se comparado com a infância e a relação mãe-filho.

Na condução deste trabalho, dois grandes eixos de discussão serão sinalizados, juntamente com suas interrogações, incoerências e plasticidades: o primeiro diz respeito à questão da paternidade - Quem quer ser pai, quem pode? Como é experienciar este lugar? Qual o espaço do pai diante da permeabilidade das fronteiras familiares? O segundo eixo se refere à adoção como uma via de acesso à paternidade - Quais são os sentidos que levam um homem a adotar? Quais são os fantasmas e medos que rondam esta temática?

Por fim, cabe situar que, com a presente investigação científica objetivou-se: compreender a experiência de ser pai adotivo. Para tanto, buscou-se conhecer possíveis modos de ser pai adotivo; problematizou-se o lugar do homem no exercício da paternidade; promoveu-se uma discussão teórica acerca da adoção; e, por fim, as narrativas foram analisadas numa perspectiva fenomenológica existencial.

\section{Dialogando entre masculinidades e paternidades}

Refletindo acerca das paternidades, estudos mostram que muitos são os modos de ser pai, contudo as requisições de modelos hegemônicos, situados em ordens de gênero, registram o masculino como provedor material e moral; e o feminino, por sua vez, é inscrito como provedor afetivo (Nolasco, 1993; Oliveira, 2010). Nessa direção, ao revelarem afetividade, seriam os pais adotivos rupturas desse "modelo tradicional"? Estariam os mesmos apontando para a emergência de novos e/ou outros modos de exercer a paternidade?

Na tentativa de ampliar tal discussão, é oportuno mencionar o anúncio de jornais, revistas e blogs a respeito do interesse de homens brasileiros para o exercício da paternidade. As leis pós Constituição Federal de 1988 refletem esse quadro: assuntos como pensão alimentícia, visitação em casos de separação conjugal, aumento do tempo da licença paternidade, adoção e guarda compartilhada concedem direitos e deveres, nunca cogitados, aos homens (Perucchi, 2008).

Organizações sociais também se levantam, continuamente, em defesa do direito e compromisso de ser pai. A ONG Papai ${ }^{1}$ é desbravadora nesse sentido. Uma de suas campanhas intitulada "Dá licença, eu sou pai!" (20082010), objetivou estimular os homens a exercerem o direito de cuidar, solicitando a licença paternidade em caso de nascimento ou adoção de um/a filho/a; bem como almejou promover mobilização pública em prol da ampliação do período da licença: de cinco para, pelo menos, trinta dias.

Na continuidade desta discussão, segundo os apontamentos de Medrado (1997), Nolasco (1993) e Oliveira (2010), o homem, na atualidade, revela-se como fenômeno de estudo, pelos canais abertos para pensar as masculinidades. No Brasil, por exemplo, essa reflexão é recente, vem tomando fôlego a partir da segunda metade da década de 90, com uma rede de diálogo fomentada principalmente por dissertações e teses voltadas ao tema.

Cabe mencionar que esse cenário ganhou maior visibilidade com a Conferência Internacional de População e Desenvolvimento (ICPD), realizada no Cairo (Egito), em 1994 e com IV Conferência Mundial sobre a Mulher, a qual ocorreu em 1995, na cidade chinesa de Beijim. Em tais espaços de discussão foi ressaltada a necessidade de maior envolvimento dos homens na vida familiar, com o intento de reequilibrar as relações de poder, a fim de atingir maior igualdade de gênero, bem como incentivar a participação masculina no campo da saúde sexual e reprodutiva.

Neste cenário, é interessante apontar a escassez de ações de saúde voltadas para o público masculino. Conforme a "Política Nacional de Atenção Integral à saúde do homem” (Ministério da Saúde, 2008), é preciso mobilizar a população masculina brasileira na perspectiva de linhas de cuidado. No que tange à paternidade, por exemplo, "é direito do homem participar de todo o processo desde a decisão de ter ou não filhos, como e quando tê-los, bem como do acompanhamento da gravidez, do parto, do pós-parto e da educação da criança” (p.20). Apesar da criação de tais diretrizes, assiste-se no cenário nacional uma tímida atenção para os direitos sexuais e reprodutivos dos homens.

Seguindo este rastro compreensivo, Trindade (1999, p. 34) discorre: "a Psicologia, que desde os seus primórdios tem nas relações familiares uma fonte inesgotável de pesquisas, não demonstrava interesse direto pela paternidade, reduzindo as relações familiares à interação mãe-filhos". Na contramão deste posicionamento, a contemporaneidade, sinaliza a presença de um pai partici-

\footnotetext{
Disponível em: <http://www.papai.org.br/> Acesso em: 14 de novembro de 2012.
} 
pante nos serviços domésticos e no envolvimento afetivo dos filhos. Tal compreensão da participação mais efetiva dos homens na família, particularmente no cuidado para com a criança, vem sendo nomeada de "nova paternidade”, a qual é vivenciada como um desejo e não mais por obrigação. A escolha de ser pai corrobora a diferença alocada entre genitor, como gerador e pai enquanto presença e investimento.

Os novos arranjos familiares, presentes no mundo inteiro, esbarram na ideia de pluriparentalidade, trazida por Uziel (2000). Essa perspectiva plural de laços desafia a lógica da primazia do biológico sobre o social; bem como aponta a paternidade adotiva enquanto uma das possíveis resistências a modelos tradicionais de paternidade.

\section{Famílias: cenário para a adoção}

Cada família tem uma história para contar... carrega na bagagem gostos, necessidades, temores, tradições, mitos e uma imensidão de sentimentos. A família, segundo Sarti (2004), pode ser compreendida como uma realidade de ordem simbólica, mundo de relações complementares, recíprocas e assimétricas, no qual o público e o privado, o nós e o outro coexistem. Sarti (2003), em outro estudo, narra a respeito de uma idealização de um modelo familiar e relaciona ao fato de que as experiências familiares são constituídas socialmente por dispositivos disciplinares religiosos, psicológicos, médicos, jurídicos e pedagógicos. Atrelado a isso, os avanços tecnológicos como a pílula anticoncepcional, a reprodução assistida e o exame de DNA repercutem na família e apontam para a inexistência de um modelo padronizado e natural de família. Mediante a coexistência de diversos arranjos familiares num mesmo contexto, a adoção aparece como um modo de ser/estar em família, diferente do "padrão" tradicional vigente de família formada por um casal heterossexual unido pelos laços do casamento e com filhos.

O transitar da paternidade biológica à paternidade social/afetiva foi aberto por influência dos novos arranjos familiares. Dorais (citado por Ramires, 1997) discute essa questão ao ponderar que, o horizonte aberto pelos diversos modos de estar em família contribui para outras roupagens às paternidades. Nessa direção, os laços biológicos entre pais e filhos não afiançam a ligação permanente entre eles, como pode ser visto em casos de separação conjugal. Por outro lado, diante de recasamentos, muitos homens exercem a parentalidade com os filhos de sua companheira, mesmo sem ligações genéticas.

O cenário social atual demanda pensar e repensar a família. Falar dela no século XXI implica considerar suas mudanças. Conforme Sarti (2003, p. 21), “com seus laços esgarçados, torna-se cada vez mais difícil definir os contornos que a delimitam”. Mediante a tal contexto, é possível observar a incoerência de tentativas de conceituação, visto os diferentes modos de vinculação en- tre pessoas. Em meio a esses entrelaçamentos, a adoção encontra habitat, o qual não é derivado de vínculos biológicos, mas sim de relações de escolha, proximidade e afeto. No tocante à adoção, segundo Schettini, Amazonas \& Dias (2006), nos contextos familiares, a mesma já foi vista como caridade, desvio da norma, saída diante da infertilidade. Todavia, vem se solidificando outra cultura de adoção, abalizada nos laços afetivos.

Nessa direção, a adoção é apresentada no presente estudo como um modo de ser família, que encontra morada entre os desejosos por filhos e os ansiosos por pais. $\mathrm{Na}$ busca de referendar o posicionamento escolhido, encontra-se respaldo na etimologia da palavra adoção: do latim, temos: $a d$ + optare, onde $a d$ = aproximação no tempo e no espaço e optare = opção. Nesse sentido, a adoção entra em cena como uma opção por aproximação, escolha de estar próximo de alguém (Weber, 2011).

Um aspecto relevante sinalizado por Schettini (2008) se refere a tendência de considerar as famílias adotivas “problemáticas". Segundo este autor, permeados por tal compreensão, muitos pais buscam a clínica psicológica a fim de "tratar" do filho adotivo, como se os laços biológicos trouxessem junto um certificado de garantia. $\mathrm{O}$ território das representações sociais negativas no tocante à adoção é ampliado no tocante as nomeadas "crianças idosas" e adolescentes, os quais se encontram no final da fila de espera por uma família. De acordo com Vargas (2006), diferentemente destas, as crianças recém-nascidas são mais escolhidas para a adoção, tendo em vista a expectativa de que poderão ser melhores educadas. Nessa direção, importa discorrer a respeito do "peso do sangue" na sociedade brasileira. Em uma cultura fundamentada na supervalorização da procriação, hereditariedade e nos laços sanguíneos, "a adoção é vista como espúrio, paralelo, inautêntico e artificial” (Schettini, 2008, p. 29). Fica subjacente pensar a ideia de criar um "filho de outra pessoa", na qual se desconhece os antecedentes psicológicos, morais, fisiológicos e até criminais assume, muitas vezes, uma conotação patológica.

A partir do contexto acima apresentado, é possível dizer que o "fantasma" dos genitores ronda a relação entre pais e filhos, pelas dúvidas outrora citadas e também frente a ameaças de perda ou de mudanças de comportamento do filho diante de sua "verdade biográfica". Sob essa ótica, é vedada, na grande maioria das vezes, a oportunidade de crianças e adolescentes terem uma família afetiva e efetiva.

Para lidar com questões como essas, a chamada Nova Lei de Adoção (Brasil, 2009) indica uma preparação prévia dos futuros pais e o acompanhamento familiar pós-acolhimento da criança ou adolescente, com o desígnio de assegurar o direito à convivência familiar. Acerca disso, cabe assinalar que o sistema jurídico não dá conta da singularidade de cada família, de cada casal, pois há sempre um vir-a-ser, um modo de ser que demanda reflexões, discussões e ações diferenciadas. 
Sendo a Psicologia estudiosa do terreno da singularidade e pluralidade humana, esta é convidada a assistir essa clientela em suas angústias, limitações e estranhezas, acolhê-la e acompanhá-la nos seus modos possíveis de serem mães e pais adotivos.

\section{Procedimentos metodológicos}

A metodologia orientadora desse trabalho é de natureza qualitativa, cujo caráter descritivo ocupa lugar de destaque (Minayo, 1994). A pretensão desta consiste em compreender os fenômenos segundo os sentidos dados pelos participantes colaboradores da pesquisa. Assim, para investigar a experiência de ser pai adotivo, utilizou-se o método fenomenológico, o qual parte do questionamento do ser. Essa postura epistemológica, diferente da chamada metafísica, assume a relatividade da verdade, afasta-se da racionalidade lógica, das hipóteses e metodologias pré-definidas (Critelli, 2007).

Em busca de interrogar o fenômeno que se manifesta, a entrevista foi escolhida como modalidade de investigação para colher os depoimentos, tomando como base a "Entrevista Clínica de Pesquisa" (Lévy, 2001, p. 90), a qual está lastreada nas narrativas reveladas a partir da questão provocadora: "Como é a experiência de ser pai adotivo?". Para este artigo apresentamos a experiência de Davi, narrador da paternidade adotiva.

A narrativa é compreendida como proposta por Benjamin (1985) - modo de comunicar a experiência, de transmitir uma tradição, de revelar sentidos. Para a compreensão dos fenômenos desvelados, o método de análise das narrativas foi a "Analítica do Sentido" de Critelli (2007). Segundo a autora, a manifestação dos fenômenos se dá por meio de um movimento de realização simultâneo entre o desvelamento, a revelação, o testemunho, a veracização e autenticação. Orientada pelos pensamentos de Martin Heidegger e de Hannah Arendt, Critelli (2007), apresenta a fenomenologia como um novo chão possível que, ao dirigir-se para o real, investiga a compreensão do sentido do ser. Este último, segundo a autora é "um rumo que apela, uma solicitação que se faz ouvir, um apelo obstinado que se insinua e persegue" (p. 146). Deste modo, a presente pesquisa expõe a construção de sentidos da experiência de homens pais adotivos não como sinônimo de significado, mas como destino, direção do existir em busca de uma compreensão.

Esta pesquisa configura-se também enquanto prática interventiva, cuja pretensão é contribuir para a produção de conhecimento e criação de sentidos no âmbito social. Assim, escrever, narrar e comunicar mostra-se como possibilidade de testemunho. Nessa direção, conforme Critelli (2007), não basta que o saber exista solitariamente, ele carece ser visto e ouvido por outros, patenteando o seu valor sócio-político.

\section{4. (Entre)vistas: possibilidades compreensivas da paternidade adotiva}

Antes de destacar as narrativas, faz-se cabível situar o leitor acerca do narrador-colaborador desta investigação. Davi ${ }^{2}$ é integrante de um Grupo de Estudo e Apoio à Adoção. Casado com Laura, teve a adoção como via de acesso à sua experiência enquanto pai. Seus filhos, Pedro e Ana são gêmeos e foram adotados quando tinham sete anos e meio. A história de vida das crianças, segundo Davi, teve o seguinte destaque: elas foram mal tratadas e abandonadas pelos genitores e, posteriormente, acolhidas em uma creche. Com um ano e meio de idade vivenciaram uma "quase adoção", ou seja, um casal obteve a guarda provisória de Ana e Pedro e, após aproximadamente três anos, os devolveu.

A respeito de Davi, este vivencia a paternidade sendo o responsável pelos cuidados diários para com as crianças, a saber: banho, refeições, idas e vindas à escola. Tal posicionamento vai de encontro à representação social de homem enquanto "figurante" na relação familiar, cabendo a este um lugar de pouca participação efetiva e afetiva no cotidiano da prole.

Outro aspecto que cabe ser situado se refere à insegurança e temor quanto a mais uma chegada do "fantasma do abandono". Ana, por exemplo, resistia em chamar Davi de pai, contudo ele a nomeava de filha. Em meio a dificuldades, esse arranjo familiar foi conquistado ao longo da convivência. Davi, nesse sentido, refere-se à adoção como via de mão dupla, patenteando a conjunção entre adotados e adotantes e colocando o afeto, não no âmbito genético, mas tecido na relação parental.

A seguir, será apontada a teia de sentidos construídos por Davi e pelas pesquisadoras, feita num processo criativo de conversação. De início, apontamos que o cuidado faz morada no exercício da paternidade adotiva. Isso pode ser evidenciado nas seguintes narrativas:

Davi - Quando a minha esposa voltou das férias eu fiquei mais com eles durante o dia! Por eu trabalhar com representação... tenho uma flexibilidade grande no horário... então era eu quem os pegava na escola... dava banho... botava para jantar!

[...] Toda madrugada eu acordo e faço o mesmo que papai fazia... ele ia no nosso quarto ver como estavam os filhos! Isso é legal porque eu os cubro e coloco o ventilador de um jeito diferente também!

[...] Por que eu o bruxo? Porque eu era o alvo... a pessoa quem tomava mais conta... quem dava a bronca e os limites!

Esses depoimentos sinalizam a ruptura do modelo hegemônico de masculinidade, o qual distancia o homem do cuidado com os filhos e o aproxima da esfera pública, do

Todos os nomes utilizados neste artigo são fictícios. 
âmbito laboral. Davi também se mostra como pai responsável por dar limites e broncas. Ele se coloca nesse lugar de dar ordens, sinalizando a perspectiva de homem como provedor moral e representante da lei. Pensando nisso, Sarti (2004) salienta, em sua pesquisa sobre famílias pobres, que cabe ao homem, além do provimento econômico, ser o chefe da família, pessoa responsável pela "boa" autoridade. A autora ressalta que esta responsabilidade masculina é digna de honra.

Encaminhando esta investigação pelas marcas das narrativas de Davi, o afeto, para ele, apresenta um caráter transformador na relação com seus filhos, permitindo a elaboração de experiências de abandono, outrora vivenciadas, e possam estabelecer vínculos de parentesco e modos outros de ser. De maneira intensa afirmou:

Davi - Ana disse 'Eu sou a princesa e o senhor é o príncipe de diamantes!' Então sair do bruxo para o príncipe de diamante foi uma conquista! Uma conquista que não foi muito minha... mas muito mais dela!

O afeto conjugado pelo narrador também aponta na direção da adoção como um modo de ser família:

Davi-Ser pai de dois filhos gêmeos... um casal... então fechou assim! Há três meses foi o batizado deles na igreja que eu faço parte... eu fiz a frase do cartão que dizia assim... Um dia pedimos a Deus dois filhos... mas ele nos deu dois anjos!

Com essa fala, podemos ver o rompimento com a indissolubilidade dos laços biológicos, ao Davi apresentar sua paternidade derivada de relações de escolhas e proximidade. Tal posicionamento contribui, significativamente, para uma nova cultura de adoção, fundamentada na afetividade (Schettini, Amazonas \& Dias, 2006).

No tocante a Davi, a ambivalência presente na paternidade adotiva personifica-se por meio do denominado "fantasma", ou seja, do receio que os filhos possuíam de outro abandono, bem como da dificuldade de adaptação dos mesmos frente a uma nova configuração familiar.

Davi - Hoje Pedro já fala tudo... ele veio dizer que entende porque brigarmos com eles... que é no intuito de educar! Nessa noite ele disse que não queria voltar mais para creche! Ouvindo isso eu disse 'filho... vocês não vão voltar mais para a creche! Você lembra daquele documento que o juiz fez?' É incrível esse fantasma!... eu sabia que isso ia acompanhá-lo por um tempo... mas eu pensei que já não havia!

Em sua narrativa Davi revela a existência de um fantasma que ronda Pedro, o qual pode ser referenciado, à luz da compreensão de estrangeiro, apontada por Figueiredo (1996) ao sinalizar que a proximidade do estranho é incômoda, visto a angústia que o mesmo pode ocasionar, bem como a dificuldade de conviver com a alteridade. Nessa perspectiva, o fantasma narrado pode carregar a marca da "outridade" da adoção, da abertura de ser família; bem como revelar o acolhimento da alteridade, do estrangeiro vindo de fora e habitante na relação parental.

Como implicação considerável ao referido "fantasma", importa problematizar que o mesmo pode estar ligado a experiência de abandono vivenciada por Pedro e Ana. Seguindo essa trilha compreensiva, Weber (2011) fez um paralelo com a clássica história infantil de João e Maria e salientou a respeito da prática do abandono de crianças, desde a Antiguidade. Diferentemente do final da história de João e Maria, muitas crianças ainda não conseguiram retornar a casa dos seus pais ou encontrar uma família. De acordo com a estimativa da Secretaria de Assistência Social, existem no Brasil cerca de "200.000 crianças abandonadas, das quais 195.000 estão em instituições” (p.36).

Dialogando com as narrativas de Davi, na tentativa de compreender a experiência da paternidade adotiva, outro ponto interessante de ser mencionado, diz respeito a: seu lugar frente às atitudes de Ana, as quais o colocavam, simultaneamente, mediante as vicissitudes do "bruxo" e do "príncipe de diamantes". O depoimento abaixo expressa um sentimento de insegurança, o qual, provavelmente, habitava em Davi ao desejar saber se seria ou não adotado enquanto pai:

Davi - Aí foi engraçado que no Carnaval desse ano fomos brincar em Olinda... fantasiados... ele foi de super homem e ela de fada! No carro ela dizia... 'vamos transformar papai em bruxo e mamãe na princesa!' [...] Eu passei a ser o príncipe de diamantes dela... veja a diferença! Para conquistar isso não foi fácil... acho que foram uns oito meses para ouvir esse príncipe de diamantes!

Na vivência da paternidade adotiva mais um fenômeno emerge, a saber, a procura de Davi por uma rede de apoio. Tal atitude é compreendida como relevante principalmente em casos de adoções de crianças maiores ou com necessidades especiais.

Davi - [...] No início da adoção ele foi acompanhado por um psicólogo e Ana por uma psicóloga! Procuramos a fonoaudióloga... mas o psicólogo já tinha sinalizado que acreditava que a gagueira era algo psicológico mesmo! [...] Na terapia eles foram mudando... Pedro foi modificando a postura... aprendendo a ser mais ele! Foi um processo muito longo! Hoje posso dizer que ele melhorou mil por cento para o que era.

As palavras de Davi trazem à tona a psicoterapia como lugar possibilitador de apropriação, no qual a existência se abre para ser compreendida e constituir-se num 
processo de co-criação, possibilitando ao cliente o desvelamento de outras formas de existir. Na tentativa de ampliar a discussão até aqui explanada, importa situar a revelação da vivência da paternidade enquanto promotora de mudanças:

Davi - Temos que nos policiar mais nas discussões... nas brigas... no que conversa e no que faz! [...] Eles dizem... 'Mamãe... papai fez isso assim... disse aquilo bem feio... andou rápido no trânsito!' Então você começa a pensar que tem família... pensar na postura pelo fato da maneira que eles me veem!

É sabido que a chegada de um novo membro provoca modificações na constelação familiar, tendo em vista que a família é um sistema aberto, passível de interferências, trocas e adaptações (Sarti, 2004). Possivelmente tornar-se pai para Davi demandou uma mudança de atitude. Seu posicionamento parece fazer coro com os achados de Rodrigues (2009) e Oliveira (2010), os quais mostram a vivência paterna enquanto produtora de maturidade, favorecedora do senso de responsabilidade frente aos filhos, fomentando, assim, um novo estágio na vida do homem.

\section{Caminhos apontados pela pesquisa}

Na compreensão de Critelli (2007, p. 27), "investigar é sempre colocar em andamento uma interrogação”. Esse querer saber que interroga foi tecido na coexistência dos horizontes das pesquisadoras, do narrador-colaborador e dos autores utilizados para tal diálogo. A partir de tal encontro emergiram possibilidades compreensivas, as quais são inesgotáveis frente a complexidade do fenômeno investigado.

Ao problematizar a paternidade adotiva, esta pesquisa aponta para outros modos de exercício da paternidade, para além da identificação do homem como provedor material/moral e "colaborador espermático" na gestação. A paternidade de Davi, por exemplo, revelou uma participação mais efetiva do homem no contexto familiar, baseada no cuidado e expressão de afeto.

Pesquisas como as de Oliveira (2010) e Rodrigues (2009) constatam a quebra das conservas culturais acima referidas e ressaltam a pluralidade de paternidades - históricas, vivenciadas, escolhidas e desejadas. Refletindo acerca da passagem da paternidade estritamente biológica para paternidades afetivas/sociais, Ramires (1997, p. 32) afirma: "essa nova perspectiva acerca da paternidade conduz necessariamente a uma mudança na política social que possa dar suporte às novas formas de exercício da paternidade”. Nessa perspectiva, a adoção pode ser pensada enquanto um facilitador para a experiência parental de um modo mais afetivo, questionando, desse modo, a "âncora” biográfica, meramente jurídica e financeira.
Ao lado dessas reflexões, esta pesquisa apontou para a distância de um rótulo pejorativo da adoção e a afirmou enquanto habitat familiar, atravessado pelo afeto. Nessa direção, é possível mencionar, para Davi, é na rede de parentesco e não na herança genética que a convivência afetiva é vivenciada e se constrói a parentalidade.

$\mathrm{O}$ anúncio da experiência de Davi revelou, por fim, a problematização a respeito do direito à convivência familiar, como fundamental à criança e ao adolescente. $\mathrm{O}$ colaborador desta pesquisa, ao adotar dois irmãos gêmeos de sete anos de idade, lançou luz a invisibilidade social de crianças maiores, as quais se encontram em instituições de acolhimento. Tal realidade aponta a carência da promoção de políticas públicas referentes a estes tipos de adoção e a precisão de divulgar, tanto para a sociedade, como aos entes públicos e civis, uma "nova" cultura da adoção acolhedora de crianças e adolescentes em suas especificidades. Weber (2011) comunga do mesmo pensamento e ressalta que, diante desse cenário, tornam-se também relevantes trabalhos de orientação e sensibilização dos pretendentes à adoção, com vistas a incentivar, esclarecer mitos e preconceitos, os quais revestem essas adoções.

Tecendo a paternidade adotiva numa perspectiva fenomenológica existencial e sabendo dos contornos flexíveis que a constituem, outra inquietação surge como abertura para problematizações posteriores: Como a práxis psicológica pode contribuir para a efetivação de Políticas Públicas relacionadas à adoção, particularmente, às chamadas “adoções necessárias” de crianças maiores, de adolescentes e daqueles que apresentam necessidades especiais?

\section{Referências}

Benjamin, W. (1985). Magia e técnica, arte e política. São Paulo: Brasiliense.

Brasil. (2009). Lei Federal N 12.010/09, de 03 de agosto de 2009. Nova Lei de Adoção. Brasília: Disponível em: htt:/www.planalto.gov.br/ccvil 03/ Ato2007-2010/2009/Lei/L12010.htm. Acesso em 05 de maio de 2012.

Critelli, M. D. (2007). Analítica do sentido: uma aproximação e interpretação do real de orientação fenomenológica. (2a Ed). São Paulo: EDUC/Brasiliense.

Figueiredo, L. C. (1996). Revisitando as Psicologias: da epistemologia à ética das práticas e discursos psicológicos. Petrópolis: Vozes.

Lévy, A. (2001). Ciências clínicas e organizações sociais: sentido e crise do sentido. Belo Horizonte: Autêntica/FUMEC.

Medrado, D. B. (1997). O masculino na mídia. Repertórios sobre masculinidade na propaganda televisiva brasileira. Dissertação de Mestrado, Pontifícia Universidade Católica de São Paulo, Programa de Estudos Pós-Graduados em Psicologia Social, São Paulo, SP. 
Minayo, M. C. de S. (1994). Ciência, técnica e arte: o desafio da pesquisa social. In: Minayo, M. C. de S.; Deslandes, S. F.; Neto, O. C.; \& Gomes, R. (Orgs). Pesquisa Social: Teoria, Método e Criatividade (p. 3-18). Petrópolis: Vozes.

Ministério da Saúde (2008). Política Nacional de Atenção Integral à Saúde do Homem. Brasília: Ministério da Saúde. Disponível em: http://dtr2001.saude.gov.br/sas/ PORTARIAS/Port2008/PT-09-CONS.pdf. Acesso em: 20 de outubro de 2011.

Nolasco, S. (1993). O mito da masculinidade. Rio de Janeiro: Rocco.

Oliveira, E. C. de. (2010). Pai, pobre e separado: entre as dificuldades e o desejo de uma paternidade plena. Dissertação de Mestrado, Pós-Graduação em Psicologia, Universidade Federal de Pernambuco, Recife, PE.

Perucchi, J. (2008). O discurso jurídico como dispositivo de produção de paternidades. Tese de Doutorado em Psicologia, Programa de Pós-Graduação em Psicologia. Universidade Federal de Santa Catarina, Florianópolis, SC.

Ramires, V. R. (1997). O exercício da paternidade hoje. Rio de Janeiro: Rosa dos ventos.

Rodrigues, L. O. (2009). Entre arranjos, circulações e rearranjos: configurações familiares no contexto da paternidade na adolescência. Dissertação de Mestrado, Pós-Graduação em Psicologia, Universidade Federal de Pernambuco, Recife, PE.

Sarti, C. A. (2004). A família como ordem simbólica. Psicologia USP, 15(3), 11-28

Sarti, C. A. (2003). Famílias Enredadas. In: Acosta, A. R.; Vitale, M. A. F. (orgs.) Família: Redes, Laços e Políticas Públicas (p. 21-36). (4a ed). São Paulo: Cortez Editora.

Schettini, L. F. (2008). Compreendendo os pais adotivos. (2a ed). Recife: Bagaço.

Schettini, S. S. M.; Amazonas, M. C. L. A.; Dias, C. M. S. (2006). Famílias adotivas: identidade e diferença. Psicologia em Estudo (Maringá), 11(2), 285-293.

Trindade, Z. A. (1999). Concepções arcaicas da maternidade e paternidade e seus reflexos na prática profissional. Interfaces: Revista de Psicologia (Salvador), 2(1), 33-40.

Uziel, A. P. (2000). "Tal pai, tal filho" em tempos de pluriparentalidade: expressão fora do lugar? In: Anais do XXIV Encontro Nacional da ANAPOCS. Petrópolis.

Vargas, M. M. (2006). Adoção de crianças maiores. In: Schettini, L. F.; \& Schettini, S. S. M. (orgs.). Adoção: os vários lados dessa história (p. 147-172). Recife: Bagaço.

Weber, L. N. D. (2011). Laços de Ternura: pesquisas e histórias de adoção. Curitiba: Juruá.
Ellen Fernanda Gomes da Silva - Psicóloga; Mestra e Doutoranda em Psicologia Clínica pela Unicap (Universidade Católica de Pernambuco), Membro do Laboratório de Psicologia Clínica Fenomenológica (LACLIFE). E-mail: ellenfernanda1@hotmail.com

Suely Emilia de Barros Santos - Mestra e Doutoranda em Psicologia Clínica pela UNICAP; Docente da Universidade de Pernambuco (UPE - Campus Garanhuns) e membro do Laboratório de Psicologia Clínica Fenomenológica (LACLIFE). E-mail: suemilia@uol.com.br

Recebido em 29.03.2013 Primeira Decisão Editorial em 18.09.2013 Segunda Decisão Editorial em 16.10.2013 Aceito em 08.05.2014 